\title{
O professor de matemática frente aos diferentes registros de repre- sentações dos números reais
}

\author{
Monique Sequeira Lehmann.
}

\begin{abstract}
PENTEADO, Cristina Berndt. Concepções do professor do ensino médio relativas à densidade do conjunto dos números reais e suas reações frente a procedimentos para a abordagem desta propriedade. 2004. 247 f. Dissertação (Mestrado) - Curso de Mestrado em Educação Matemática, PUC/SP, São Paulo, 2004.
\end{abstract}

Cristina Berndt Penteado possui graduação em Matemática pela Pontifícia Universidade Católica de São Paulo(1989), graduação em Licenciatura em Matemática pela Pontifícia Universidade Católica de São Paulo (1989), e mestrado em Educação Matemática pela Pontifícia Universidade Católica de São Paulo (2004). Atualmente é Professora assistente do Fundação Armando Álvares Penteado e Calculista Judicial da Gueller portanova vidutto sociedade de advogados. Tem experiência na área de Matemática. Atuando principalmente nos seguintes temas: Densidade, Números Reais, Registros de Representação Semiótica.

A pesquisa foi realizada como requisito parcial para obtenção do título de Mestre em Educação Matemática pelo Programa de Pós-Graduação em Educação Matemática da Pontifícia Universidade Católica de São Paulo. Orientada pelo Prof Dr. Benedito Antonio da Silva, a obra foi dividida em 6 capítulos: A problemática, A representação decimal dos números reais, Fundamentação teórica, Procedimentos metodológicos, Análise dos resultados e Conclusões, totalizando 247 páginas.

O principal objetivo do estudo foi investigar a concepção e a reação dos professores do Ensino Médio frente aos diferentes registros de representações dos números quando analisada a propriedade da densidade dos números racionais e irracionais no conjunto dos reais. Foi investigada a viabilidade de dois procedimentos (Média aritmética e Diagonalização de Cantor) para a obtenção de números reais entre dois dados.

A pesquisa foi embasada na Teoria dos Registros de Representação Semiótica, do psicólogo francês Raymond Duval, que propõe a utilização de registros de representação da língua: natural, decimal, fracionário e gráfico. Duval defende que a apreensão do objeto matemático se dá quando o sujeito consegue transitar de uma representação a outra, utilizando diferentes tipos de registros de representação. Segundo ele, é necessário produzir uma representação para se chegar a conceitualização.

A metodologia se deu através da elaboração, aplicação e análise de uma seqüência de ensino baseada em dez atividades e dividida em dois procedimentos. Para isso, foram utilizados os princípios da Engenharia Didática propostos por Michele Artigue, baseados na comparação entre a análise à priori e a análise posteriori, e possibilitando validar ou não as hipóteses levantadas inicialmente. A engenharia didática é um esquema experimental, que se baseia em relações didáticas em sala de aula, através da concepção, realização, observação e análise das sequências de ensino. O primeiro procedimento utilizado na pesquisa, através da média aritmética, foi utilizado para discutir a densidade dos racionais nos reais e envolve os registros de representação fracionário, decimal e gráfico. Para discutir a densidade dos irracionais nos reais foi utilizado o processo de diagonalização de Cantor, através dos registros decimal e gráfico.

Os sujeitos pesquisados foram um grupo de 11 professores do ensino médio da rede pública do Estado de São Paulo, participantes do PEC (Projeto de Educação Continuada). De acordo com a autora, a justificativa pela escolha de professores é pelo fato de que estes são os agentes do processo ensino-aprendizagem que tem influência sobre um grande número de alunos.

As atividades propostas, duas a duas, foram divididas em grupos e distribuídas por 5 sessões, correspondendo a 5 dias de trabalho. Os professores foram divididos em duplas e acompanhados pela pesquisadora, que em alguns momentos fezintervenções, e por um observador, que se restringiu em anotar os comentários sem dialogar com os participantes. 
A primeira sessão iniciou com o preenchimento do questionário do perfil acadêmico e profissional, e a última teve o preenchimento do questionário de avaliação da sequência de ensino.

A seqüência de ensino foi dividida em 10 atividades, cada uma delas composta por várias questões e suas respectivas discussões. A atividade I, composta de 4 questões, teve como objetivo chamar a atenção quanto à classificação dos números reais em racionais e irracionais, além de iniciar um trabalho sobre a noção de densidade do conjunto dos reais. A atividade II foi elaborada com o intuito de atingir mais pontualmente a noção de densidade através do registro da língua natural. É composta de uma única questão do tipo verdadeirofalso na qual devem ser julgadas 14 afirmações, com seus respectivos comentários. Seguindo a abordagem de Niven (1984), as questões foram formuladas explorando várias situações, incluindo casos em que uma proposição é verdadeira, mas sua recíproca não é necessariamente verdadeira também. Na atividade III iniciou-se o trabalho com a noção de densidade do conjunto dos números racionais no conjunto dos reais, através de 16 questões que envolvem dois números reais distintos. A atividade IV envolve dois números com irracionais cuja parte decimal sugere uma sequência e tem como objetivo discutir a situação de que entre dois números irracionais distintos, existem infinitos números irracionais. Na atividade $\mathrm{V}$, composta de 11 questões, a proposta foi chamar a atenção quanto à relação entre periodicidade ou não da representação e a racionalidade ou não do número. A atividade VI discute a existência de infinitos números irracionais entre dois racionais. Nas questões desta atividade foram utilizados dois números racionais com registros de representação diferentes (decimal infinita e fracionária).

Segundo a autora, para que haja apreensão de um objeto matemático não basta apenas uma discussão ou um momento de apreensão e, sendo assim a atividade VII contém questões semelhantes às atividades III e VI. Foram abordadas situações: de números irracionais entre dois racionais, de números irracionais entre um racional e outro irracional e de números irracionais entre um irracional e outro racional. As questões da atividade VIII tiveram a mesma estrutura da atividade anterior, e foram pedidas a obtenção de números racionais e irracionais entre dois números dados em relação à esquerda e à direita. $\mathrm{Na}$ atividade IX foram fornecidos dois números irracionais para abordar a existência de números (racionais e irracionais) entre eles, englobando e repetindo os objetivos das atividades IV e $\mathrm{V}$ e retornando os critérios de classificação de números racionais e irracionais na representação decimal infinita. A última atividade, com 14 questões do tipo verdadeirofalso, semelhante à atividade II, objetiva verificar se há concepções como a identificação de número irracional com a representação decimal infinita, identificação da representação fracionária como número racional e a possível identificação de número irracional com sua aproximação a um número racional. Nesta atividade foram contempladas todas as situações abordadas nas questões anteriores.

Para traçar um diagnóstico dos resultados, a autora, pautada nos objetivos e expectativas da análise a priori, analisou cada uma das respostas das questões e os comentários feitos durante a resolução. Além disso, foi examinado o instrumento de avaliação do experimento, respondido pelos participantes no final da última sessão. A atividade II foi reaplicada dois meses depois e reanalisada.

$\mathrm{Na}$ atividade I, sobre a classificação de números em racionais e irracionais, observou-se que a maioria dos sujeitos classificou corretamente os números dados. $\mathrm{O}$ zero, que historicamente gera dificuldades de ser aceito como número, foi classificado em racional e irracional ao mesmo tempo. Sobre a existência de números reais entre dois racionais dados, todos acertaram as questões e forneceram exemplos. A atividade II, além do caráter diagnóstico, foi utilizada para a preparação das atividades seguintes. A questão que mais gerou erros foi "entre dois números irracionais existe um número racional". A análise das discussões permitiu concluir que além da linguagem matemática, é necessária a representação da língua natural, como defende Duval em sua teoria. Na atividade IV, cujo objetivo era verificar a existência de números racionais entre dois racionais através da utilização da média aritmética, observou-se que todos chegaram à conclusão correta. $\mathrm{Na}$ atividade $\mathrm{V}$, cuja questão central era a obtenção de um número irracional entre dois irracionais, a maioria dos sujeitos percebeu a necessidade de troca de algarismos na representação decimal infinita para gerar outro irracional. Nas questões da atividade VI, que abordaram a existência de infinitos números irracionais entre dois racionais, verificou-se que a representação das reticências gerou dúvidas, que alguns grupos identificaram que dízimas periódicas representam números racionais e, apesar das argumentações não serem as esperadas, todos os grupos responderam que há infinitos irracionais entre dois racionais dados. A atividade VII, com 14 questões envolvendo números racionais e irracionais muito próximos, gerou muitas discussões e reflexões. Observou-se que para alguns, a infinitude da representação foi associada à irracionalidade do número, enquanto que outros indicaram que dízima refere-se a número racional. $\mathrm{Na}$ atividade VII, cujo objetivo principal foi instigar os participantes a obter números racionais e irracionais entre números muito próximos $(3,14$ e $\pi)$, foi possível observar que, de modo geral, a maioria dos sujeitos escreveram os números dados para depois inserir o número pedido. Quanto à propriedade da densidade da reta, ficou evidente que esta não está clara para todos os 
participantes. Observou-se também que a representação decimal infinita gerou muitas, talvez por não ser tão enfatizada no ensino médio. As questões da atividade IX tiveram como objetivo a obtenção de números racionais e irracionais entre dois irracionais dados $(0,10100100001 \ldots$ e $0,10100100010 \ldots)$, englobando as mesmas situações da atividade anterior. Foi possível perceber entre alguns sujeitos a observação de que os intervalos estavam diminuindo a cada atividade e que, mesmo assim, ainda é possível encontrar infinitos números entre os dados. A atividade $\mathrm{X}$, com 14 questões do tipo verdadeiro-falso objetivou comparar as concepções identificadas na atividade II. Observou-se uma evolução considerável nas respostas, com apenas 2 erros (enquanto que na atividade II foram 12 erros em 14 questões). Além disso, as justificativas apresentadas tiveram argumentos mais elucidativos.

Ao final da última sessão, os participantes responderam a um questionário a respeito da sua opinião sobre a sequência de ensino. Foram questionados sobre: do que tratou a sequência, os três tópicos mais relevantes, o que aprenderam, as dúvidas que permaneceram, se recomendariam a atividade e que sugestões de mudanças apresentariam. A maioria dos professores salientou a classificação dos números racionais e irracionais nas diferentes representações como assunto principal. A noção de densidade foi pouco citada, mas apareceu em algumas respostas.

Dois meses após a aplicação da sequência de ensino, as questões da atividade II foram reaplicadas aos professores. De acordo com a autora, a escolha por esta atividade se deve ao fato de que envolve questões que abordam mais especificamente o tema principal da pesquisa, ou seja, a densidade dos números reais. Nesta segunda etapa, as atividades foram aplicadas individualmente. Todos classificaram corretamente as questões como verdadeiro ou falso, com exceção de um professor que errou uma única questão. Apesar de ter havido algumas confusões nas escolhas dos números pedidos, observou-se que houve grande preocupação dos sujeitos em justificar as questões através de exemplos numéricos ou da língua natural.

É importante destacar que todas as dúvidas e discussões que surgiram ao longo da realização da sequência de ensino foram trabalhadas durante as atividades. A maioria dos sujeitos, ao responder questões, recorreu às suas respostas anteriores, como uma tentativa de reprodução do procedimento sugerido em atividades anteriores. De maneira geral, observou-se boa receptividade por parte dos professores e as questões foram desenvolvidas com seriedade, entusiasmo e grande empenho.

Como sugestão da autora, uma possível continuação do trabalho seria a elaboração de atividades em conjunto com os professores, a serem aplicadas a seus alunos. 